\title{
A Two-Step Method for the Preparation of Highly Conductive Graphene Film and Its Gas-Sensing Property
}

\author{
Tran Van Khai ${ }^{*}$, Tran Dai Lam², Le Van Thu3 ${ }^{3}$ Hyoun Woo Kim ${ }^{4}$ \\ ${ }^{1}$ Faculty of Materials Technology, Ho Chi Minh City University of Technology, Ho Chi Minh City, Vietnam \\ ${ }^{2}$ Institute of Material Science, Vietnam Academy of Science and Technology, Hanoi, Vietnam \\ ${ }^{3}$ Institute of Chemistry-Biology and Professional Documents, Ministry of Public Security, Hanoi, Vietnam \\ ${ }^{4}$ Division of Materials Science and Engineering, Hanyang University, Seoul, Republic of Korea \\ Email: *tvkhai1509@gmail.com
}

Received 24 September 2015; accepted 15 November 2015; published 18 November 2015

Copyright (C) 2015 by authors and Scientific Research Publishing Inc.

This work is licensed under the Creative Commons Attribution International License (CC BY). http://creativecommons.org/licenses/by/4.0/

(c) (i) Open Access

\begin{abstract}
In this research, a highly conductive graphene film was synthesized through the chemical reduction of graphene oxide (RGO) nanosheets followed by thermal treatment at $1100^{\circ} \mathrm{C}\left(\mathrm{RGO}^{-1100}{ }^{\circ} \mathrm{C}\right)$ under $\mathrm{H}_{2}$ ambient. The as-prepared graphene films were characterized by using $\mathrm{X}$-ray photoelectron spectroscopy, fourier transform infrared spectroscopy, X-ray diffractions, raman spectroscopy, transmission electron microscopy, scanning electron microscopy, atomic force microscopy and by electrical conductivity measurements. The results showed that the thermal treatment efficiently removed residual oxygen-containing functional groups on the surface of the RGO sheets and simultaneously restored the $\mathrm{sp}^{2}$ carbon networks in the graphene sheets. As a result, the electrical conductivity of $R G O-1100^{\circ} \mathrm{C}(\sim 210 \mathrm{~S} / \mathrm{cm})$ film was greatly improved compared with that of RGO $(\sim 24 \mathrm{~S} / \mathrm{cm})$ and graphene oxide $\left(4.2 \times 10^{-4} \mathrm{~S} / \mathrm{m}\right)$ films. In addition, the $\mathrm{NO}_{2}$ gas sensing characteristics of the as-prepared RGO films were studied. The results indicated that RGO films were highly responsive to $\mathrm{NO}_{2}$ at temperature of $200^{\circ} \mathrm{C}$.
\end{abstract}

\section{Keywords}

Graphene, Graphene Oxide, Graphene-Film, Thermal Reduction

\section{Introduction}

Graphene, a single layer of $\mathrm{sp}^{2}$-hybridized carbon atoms in a hexagonal two-dimensional lattice, has attracted ${ }^{*}$ Corresponding author. 
tremendous attention due to its unique physical and chemical properties and potential applications in many fields, including nanoelectronic, sensor for biomolecules, transistors, solar cell and catalysts [1]-[4]. Up to now, there are major methods having been developed to synthesize graphene, including mechanical exfoliation, epitaxial growth, bottom-up synthesis and chemical reduction of graphene oxide suspension. The last method is considered to an efficient approach to produce graphene sheets in bulk quantity at relatively low cost.

Currently, the Hummers' method is the most widely used technique for preparing graphene oxide (GO) [5], which involves oxidation of graphite in the presence of strong acids and oxidants. When oxidized, GO still possess a layered structure, being composed of unoxidized aromatic regions and aliphatic regions, which contain many oxygen functional groups [6] [7]. The $\pi$-conjugated system in graphene is disrupted by these oxygencontaining functional groups, producing separated nanocrystalline graphene. Since the as-prepared GO is an electrical insulator, various reduction methods have been developed to efficiently recover its electrical property [8]-[11]. Chemical reduction of GO is one of the most promising methods to realize low-cost and high-throughput preparation of converted graphene with excellent process ability [12]. However, the chemically RGO sheets still exhibit much lower conductivity than pristine graphene, mainly due to the presence of irreversible defects, disorder and residual functional groups. Therefore, it is necessary to develop a more effective reduction method to produce graphene-like film with high electrical conductivity. Recently, it is demonstrated that thermal annealing is the most effective method capable of removing oxygen from GO films, where reduction is accomplished by decomposition of oxygen containing groups and simultaneous restoration of $\mathrm{sp}^{2}$ carbon networks [13]. Hence, high-temperature annealing is required to repair the defects and further remove the residual functional groups in RGO sheets to improve its electrical properties.

Because the graphene film possesses nanometric thickness, high electrical conductivity, high aspect ratio, and good mechanical property; it has been regarded as a promising material for gas sensor devices. Recent studies on the interaction of graphene with gas molecules have indicated that it can act as a good sensor [14]-[21]. Schedin and co-workers [19] have shown that the increase in the charge carrier concentration induced by gas molecules adsorbed on the surface of graphene can be used to fabricate sensitive gas sensors. Based on theoretical investigations on the adsorption of gas molecules on single-layer graphene as well as on graphene nanoribbons, it has been predicted that the doping in carbon nanostructures may improve the sensitivity [22]-[25]. Ao and co-workers have applied density functional theory to show that aluminium doped graphene can be used as a good detector for carbon monoxide [26]. Functionalized graphite nanostructures are able to sense traces of pollutant gases such as $\mathrm{NO}_{2}$ [27]. Water vapor sensing characteristics of RGO has been studied [28]. RGO is also shown to be good sensor for toxic vapors [29]. Spin-coated hydrazine functionalized graphene dispersions are able to detect $\mathrm{NO}_{2}, \mathrm{NH}_{3}$, and 2,4-dinitrotoluene [30]. However, very little work has reported about $\mathrm{NO}_{2}$ gas sensor based on graphene film prepared through thermal reduction of RGO films.

In this paper, we employed a simple method for the preparation of highly conductive graphene films through the chemical reduction of GO and subsequent thermal annealing at $1100^{\circ} \mathrm{C}$ in $\mathrm{H}_{2}$ ambient. We have studied the relation between structure and electrical conductivity of the graphene films upon reduction. Further, the $\mathrm{NO}_{2}$ gas sensors based on the RGO films have been fabricated onto the Pt electrodes on a quartz substrate and studied. It is considered to be important to examine gas sensing characteristics of graphene films prepared by chemical and thermal reduction.

\section{Experiments}

\subsection{Materials}

Graphite powder (Qingdao Yanshou Graphite Co., Ltd. Qingdao Branch, China), $\mathrm{H}_{2} \mathrm{SO}_{4}$ (98\%, Viet Nam), $\mathrm{H}_{3} \mathrm{PO}_{4}$ (98\%, Viet Nam), $\mathrm{KMnO}_{4}$ (98\%, Japan) and $\mathrm{H}_{2} \mathrm{O}_{2}$ (30 wt\%), Hydrazine monohydrate (98\%, Otsuka Chemical Co., Ltd., Japan), N,N-Dimethylformamide (DMF, 99.8\%, Otsuka Chemical Co., Ltd., Japan) were obtained from commercial resources and used as received.

\subsection{Fabrication of Graphene Films and Sensor Device}

GO was synthesized from graphite powder via a modification of Hummers and Offeman's method [5]. In a typical reaction, $5 \mathrm{~g}$ of graphite, $60 \mathrm{~mL}$ of $\mathrm{H}_{3} \mathrm{PO}_{4}$, and $180 \mathrm{~mL}$ of $\mathrm{H}_{2} \mathrm{SO}_{4}$ were stirred together with a Teflon-coated magnetic stirring in an ice bath. Next, $60 \mathrm{~g}$ of $\mathrm{KMnO}_{4}$ was slowly added while the temperature was maintained 
at $0^{\circ} \mathrm{C}$. Once mixed, the solution is transferred to a $35^{\circ} \mathrm{C} \pm 5^{\circ} \mathrm{C}$ water bath and stirred for $3 \mathrm{~h}$, forming a thick paste. Next, distilled water $(450 \mathrm{~mL})$ was slowly dropped into the resulting paste to dilute the mixture, and then the solution was stirred for $1 \mathrm{~h}$ while the temperature was raised to $90^{\circ} \mathrm{C} \pm 5^{\circ} \mathrm{C}$. Finally, $800 \mathrm{~mL}$ of distilled water was added, followed by the slow addition of $60 \mathrm{~mL} \mathrm{H}_{2} \mathrm{O}_{2}(30 \%)$, turning the colour of the solution from dark brown to yellow. During this final step, $\mathrm{H}_{2} \mathrm{O}_{2}$ (30\%) reduced the residual permanganate and manganese dioxide to colourless soluble manganese sulphate. The GO deposit was collected from the GO suspension by high speed centrifugation at 15,000 rpm for $30 \mathrm{~min}$. The obtained GO was then washed with $1000 \mathrm{~mL}$ of $\mathrm{HCl}(5 \%)$, and repeatedly washed with distilled water until the $\mathrm{pH}=7$. To obtain uniform GO, a low-speed centrifugation at $3000 \mathrm{rpm}$ was first used to remove thick multilayer sheets until all the visible particles were removed ( 3 - $5 \mathrm{~min}$ ). Then the supernatant was further centrifuged at 10,000 rpm for $30 \mathrm{~min}$ to remove small GO pieces and watersoluble by product. The final sediment was redispersed in $500 \mathrm{ml}$ of DMF with mild sonication, resulting in a solution of exfoliated GO. The exfoliated GO nanosheets were chemically reduced to graphene in the presence of hydrazine. Typical, $500 \mathrm{ml}$ of above exfoliated GO was stirred for $30 \mathrm{~min}$, and $10 \mathrm{ml}$ of hydrazine monohydrate was added. The mixtures were heated at $150^{\circ} \mathrm{C} \pm 5^{\circ} \mathrm{C}$ using an oil bath for $24 \mathrm{~h}$; a black solid precipitated (called RGO) from the reaction mixtures. Products were collected by centrifugation at 12,000 rpm for 45 minutes and washed with deionized water and methanol until the $\mathrm{pH}=7$. Next, to generate a homogenous colloidal suspension of RGO, the obtained RGO was redispersed in DMF, and then the mild sonication was applied for 60 minutes to form a homogenous RGO suspension. Subsequently, the RGO suspension was sprayed on quartz substrates using the air-brush system with $\mathrm{Ar}$ as a carrier gas. A horizontal quartz tube furnace was used for annealing RGO films at $1100^{\circ} \mathrm{C}\left(\mathrm{RGO}-1100^{\circ} \mathrm{C}\right)$ under a mixture of argon (Ar) and hydrogen $\left(\mathrm{H}_{2}\right)$ gas. The films were put on the top of the alumina boat is then introduced into the quart tube reactor filled with $\mathrm{Ar}+\mathrm{H}_{2}$ gas $\left(20 \% \mathrm{H}_{2}\right)$. To avoid burning of GO films at high temperature due to the self-released oxygen from GO sheets, the quartz tube was evacuated to about $10^{-2}$ Torr using rotary vacuum pump. Next, the system is first heated for $180 \mathrm{~min}$ at $250^{\circ} \mathrm{C}$ to remove all the moisture with $\left(\mathrm{Ar}+\mathrm{H}_{2}\right)$ gas flowing at a rate of $100 \mathrm{sccm}$. Subsequently the temperature was raised to $1100^{\circ} \mathrm{C}$ in $60 \mathrm{~min}$. The annealing reaction was carried out for $30 \mathrm{~min}$. Finally, the system was naturally cooled down to room temperature at constant $\left(\mathrm{Ar}+\mathrm{H}_{2}\right)$ flow rate of $100 \mathrm{sccm}$. To evaluate the sensing behavior of the RGO films, we have sprayed the RGO suspension onto the interdigitated Pt electrode on a quartz substrate, followed by thermal treatment with the same conditions as mentioned above.

\subsection{Characterization of the As-Synthesized Materials}

The microstructures of the GO, RGO and as-synthesized films were investigated by using scanning electron microscope (SEM, JEOL, JSM-5900 LV, Japan). Atomic force microscope (AFM) image was obtained on an AFM XE-100 (Park system) equipped. High-resolution transmittance electron microscope (HR-TEM) was conducted on a TECNAI 20 microscope operated at $200 \mathrm{kV}$. X-ray diffraction (XRD) characterization was performed using $\mathrm{Cu} \mathrm{K \alpha}$ (wavelength at $1.54 \AA$ ) radiation, $40 \mathrm{kv}, 30 \mathrm{~mA}$, Rigaku, Japan. The Fourier transform infrared (FT-IR) spectra (500 - $4000 \mathrm{~cm}^{-1}$ ) were measured using a (Nicolet IR100 FT-IR) spectrometer with KBr (99\%) as background. The Raman spectroscopy measurements were recorded using a Jasco Laser Raman Spectrophotometer NRS-3000 Series, with an excitation laser wavelength of $532 \mathrm{~nm}$, at a power density of 2.9 $\mathrm{mW} \cdot \mathrm{cm}^{-2}$. X-ray photoelectron spectroscopy (XPS, VG Multilab ESCA 2000 system, UK) analysis using a monochromatized $\mathrm{Al} \mathrm{K} \alpha \mathrm{X}$-ray source $(h v=1486.6 \mathrm{eV})$ was performed to analyze the elemental compositions and the assignments of the carbon peaks of the samples. The current-voltage (I-V) characteristic is examined by using four point probes with Keithley 2400 Source-meter. Preliminary current measurements in a gas sensor characterization system (GSCS) were performed exposing the device. Sensing characteristics were evaluated at various $\mathrm{NO}_{2}$ concentrations, in the range of $10-50 \mathrm{ppm}$, at an operating temperature of $200^{\circ} \mathrm{C}$ under atmospheric pressure.

\section{Results and Discussion}

\subsection{Morphology and Structure}

Figure 1(a) \& Figure 1(b) shows SEM image of graphite powers used as staring material with a wide size range of the particles, where the dimensions are about $3-7 \mu \mathrm{m}$ in width and several hundreds of $\mathrm{nm}$ in thickness 

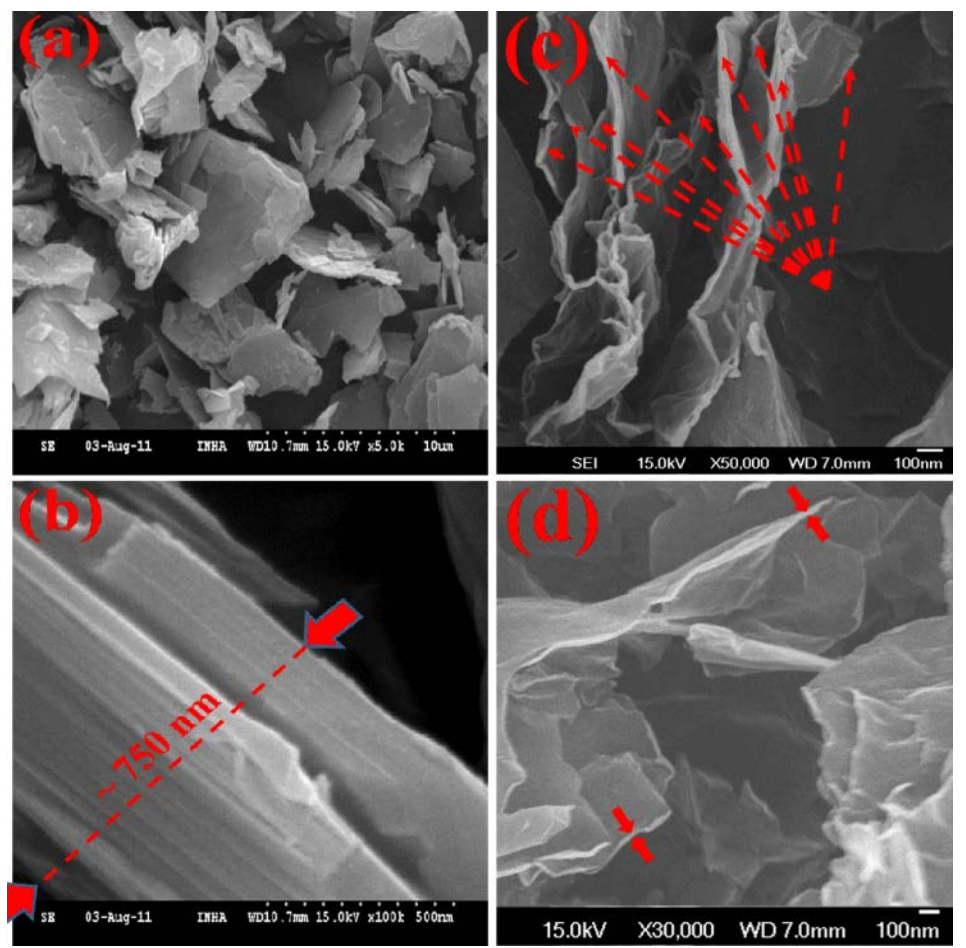

Figure 1. SEM images of graphite powders (a) \& (b) and of GO (c) \& (d).

( 750 nm) with flake-shape. Figure 1(c) \& Figure 1(d) reveals SEM image of GO nanosheets. The result indicates that the average particle size dramatically reduces after the oxidation process. During the oxidation reaction of graphite powder with concentrated sulfuric acid and phosphoric acid, $\mathrm{H}_{2} \mathrm{O}$ molecules, $\mathrm{PO}_{4}^{3-}$ and $\mathrm{SO}_{3}^{2-}$ cations were inserted into the graphene layers and expanded the interlayer spacing in the graphite crystal structure [7]. The graphite oxide can be effectively exfoliated via ultrasonic vibration to create GO nanosheets. Further observation of morphology has been achieved though TEM. As shown in Figure 2(a), the transparent GO nanosheets exist in the form of thin few-layer grephene with folds and wrinkles. The edges of the GO nanosheets are distinguishable, and found to contain a tri-layer GO flake, as shown in the inset of Figure 2(a). Wrinkles and folds are very evident on the surface of the GO nanosheets; these are characteristic of thin and two-dimensional (2D) GO. The AFM image (Figure 2(b)) also shows a 2D GO nanosheet with wrinkle-like features, and the apparent thickness is ca. $1.2 \mathrm{~nm}$, which is comparable to the literature data (1.25 nm) for the bi-layer GO nanosheet as reported before [31]. Theoretically, the single-layer graphene sheet is atomically flat with a wellknown van der Waals thickness of $0.34 \mathrm{~nm}$, while GO sheets are expected to be "thicker" due to the presence of covalently bound oxygen and the displacement of the $\mathrm{sp}^{3}$-hybridized carbon atoms slightly above and below the original graphene plane. Some researchers [32] pointed out that the heights of "dry" and hydrated GO were about $0.65-0.75 \mathrm{~nm}$ and $1.2 \mathrm{~nm}$, respectively. Therefore, in this paper, the GO nanosheets may be composed of a bi- and/or tri-layer of GO sheets, being in good agreement with the TEM result.

Figure 3(a) displays a typical TEM image of RGO sheets. It is observed that the RGO sheet is made of 3-4 layers, as shown in the bottom right-corner of Figure 3(a). The increase in number of layers of RGO compared to GO can be due to aggregation of graphene sheets after chemical reduction process, similar to the previous studies [33] [34]. The crystallographic structure of the RGO is determined by using the selected area electron diffraction (SAED) technique, as shown in the inset of Figure 3(a). The SAED yields a ring-shaped pattern consisting of many diffraction spots for each order of diffraction. These spots make regular hexagons with different rotational angles, indicating the presence of few layers in the RGO assembly. Furthermore, this result confirms that the typical six-fold symmetry of the pattern comes from the crystallographic structure of the graphene composed by carbon atoms arranged in a strictly two-dimensional honeycomb-in real space. Figure 3(b) and Figure 3(c) show two-dimensional (2D) and three-dimensional (3D) AFM images of RGO- $1100^{\circ} \mathrm{C}$ films, respectively. AFM images of RGO- $1100^{\circ} \mathrm{C}$ films revealed that the $\mathrm{RGO}-1100^{\circ} \mathrm{C}$ sheet sizes of a few microns 

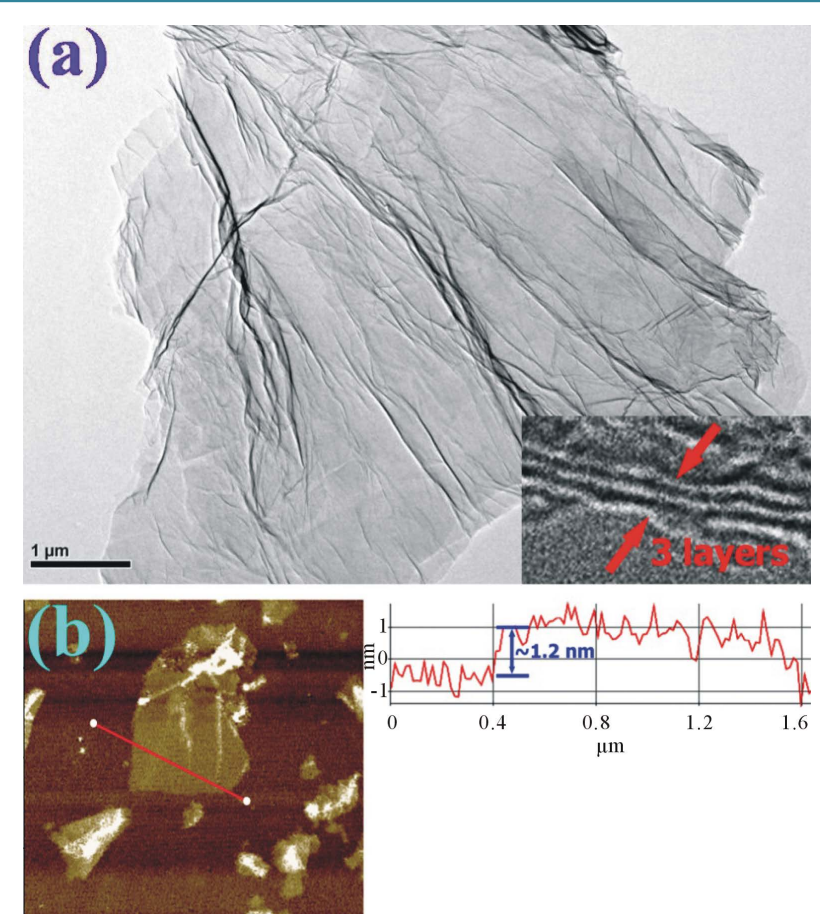

Figure 2. TEM image of GO (a) and AMF image of GO (b) and the height profile in selected location.
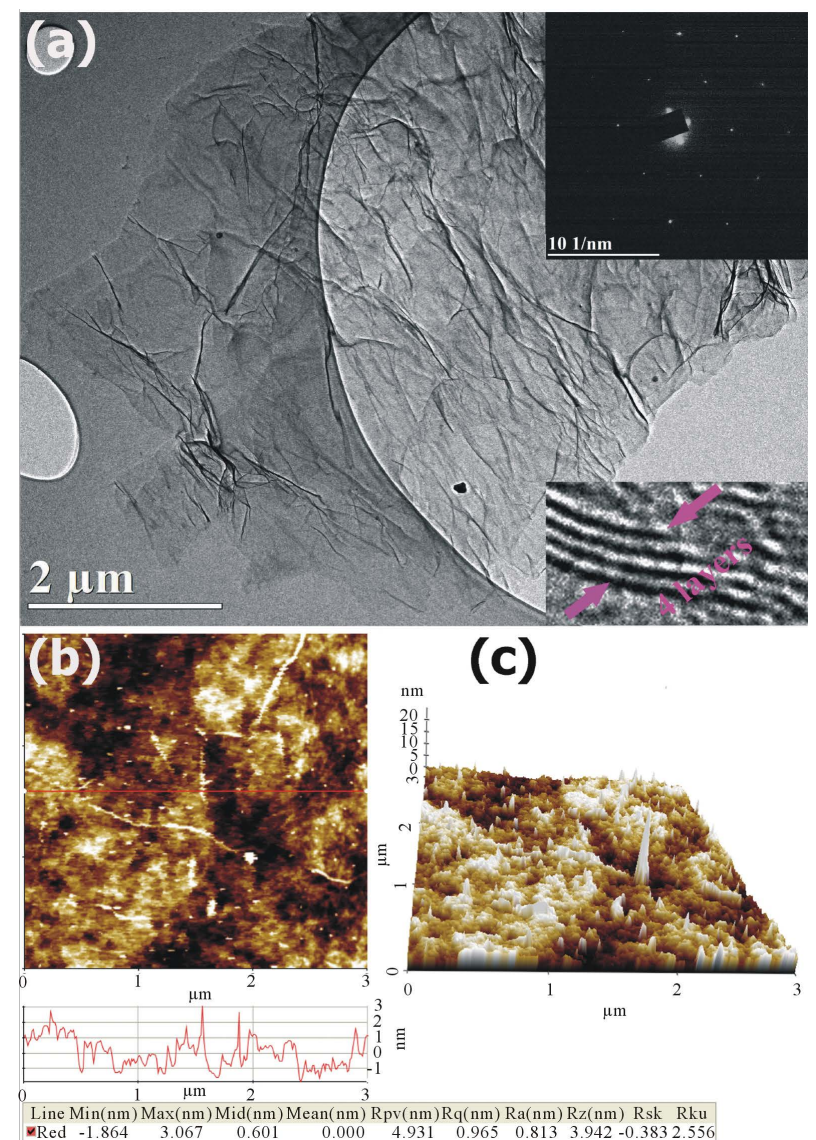

Figure 3. (a) TEM of RGO nanosheets. The inset in Figure 3(a) is corresponding selected area electron diffraction (SAED); (b) Two-dimensional; and (c) three-dimensional AFM images of RGO- $1100^{\circ} \mathrm{C}$ films. 
were randomly deposited an overlapped one another to create a continuous thin film with long, broad wrinkles or folds. In spite of the formation of the wrinkles and folds across the film surface, the surface root mean square roughness $\left(\mathbf{R}_{\mathbf{q}}\right)$ was estimated to be about $0.965 \mathrm{~nm}$, which is comparable to that of the reduced GO film prepared by the same method [35].

Figure 4 shows the XRD patterns of raw graphite, GO, RGO and RGO- $1100^{\circ} \mathrm{C}$ films. The raw graphite showed a very strong (002) peak at $26.40^{\circ}$, corresponding to interlayer distance (d-spacing) of about $3.37 \AA$. However, after oxidation, the (002) peak shifted to a lower angle of around $11.90^{\circ}$, corresponding to the dspacing of $7.43 \AA$. Such d-spacing is significantly larger than that of single-layer graphene ( 3.36 $\AA$ ), indicating that GO contains large numbers of oxygen-containing functional groups on both sides of the graphene sheets. For RGO sample, the peak disappeared in a region of low angle and another broad peak at $22.19^{\circ}$ corresponding to d-spacing of $4.0 \AA$ appeared. This indicated that a large number of functional groups on the surface of GO was removed during chemical reduction process. As the RGO films was annealed at $1100^{\circ} \mathrm{C}$, the (002) peak became sharper and shifted to higher angle of $25.30^{\circ}$. The d-spacing of RGO- $1100^{\circ} \mathrm{C}$ films was decreased to 3.51 $\AA$, which is smaller than of RGO, suggesting that thermal annealing further removed the residual oxygen-containing functional group on the surface of RGO sheets. The XRD results clearly indicated that thermal annealing enables a better ordering of the $2 \mathrm{D}$ sheets. Note that d-spacing of the $\mathrm{RGO}-1100^{\circ} \mathrm{C}$ film is slightly greater than, but quite close to, that of graphene layers in graphite, indicating that RGO- $1100^{\circ} \mathrm{C}$ sheets are similar to the pristine sheets. The slightly increased d-spacing of RGO- $1100^{\circ} \mathrm{C}$ films can be attributed to the presence of a small amount of residual oxygen-containing functional groups or other structural defects.

Figure 5(a)-(c) shows the FT-IR spectra of GO, RGO and RGO- $1100^{\circ} \mathrm{C}$ films. The FT-IR spectrum of GO exhibits a strong and broad band at $3400 \mathrm{~cm}^{-1}$, which is due to the $\mathrm{O}-\mathrm{H}$ stretching vibration. The band at 1724 $\mathrm{cm}^{-1}$ is related to the $\mathrm{C}=\mathrm{O}$ stretching motions of $\mathrm{COOH}$ groups at the edges of the sheets [36]. The band at 1622 $\mathrm{cm}^{-1}$ can be due to the O-H bending vibration of absorbed water. The peak at $1384 \mathrm{~cm}^{-1}$ can be attributed to $\mathrm{OH}$ deformation vibration mode [36]. The spectrum also shows two peaks at 1233 and $1074 \mathrm{~cm}^{-1}$, being originated from the C-O stretching vibrations of epoxy and alkoxy, respectively [36] [37]. In the FT-IR spectrum of the RGO, the peaks at 1724, 1834 and $1233 \mathrm{~cm}^{-1}$ were disappeared. The intensity of peak at $1089 \mathrm{~cm}^{-1}$ (C-O), 1725 $\mathrm{cm}^{-1}(\mathrm{C}=\mathrm{O})$ and broad peak at $3400 \mathrm{~cm}^{-1}$ were markedly reduced, indicating the removal of the hydroxyl and carboxylic acid groups. It did not completely disappear because of the mild reaction conditions. In addition, there are three new bands at 1557, 1433 and $1198 \mathrm{~cm}^{-1}$ appeared in the spectrum of RGO. The band at 1557 corresponds to aromatic $\mathrm{C}=\mathrm{C}$ bonds [36], indicating the restoration of the $\mathrm{sp}^{2}$ carbon networks during chemical reduction. The two bands at 1433 and 1198 are attributed to sp ${ }^{3} \mathrm{C}-\mathrm{N}$ [38] and C-N [39] stretching modes, respectively. After thermal annealing, the spectrum of RGO- $1100^{\circ} \mathrm{C}$ shows only two bands at $1545(\mathrm{C}=\mathrm{C})$ and 1213 (C-N stretching) $\mathrm{cm}^{-1}$, suggesting the effectiveness of thermal annealing in removing the residual oxygen functional groups on the surface of RGO sheets.

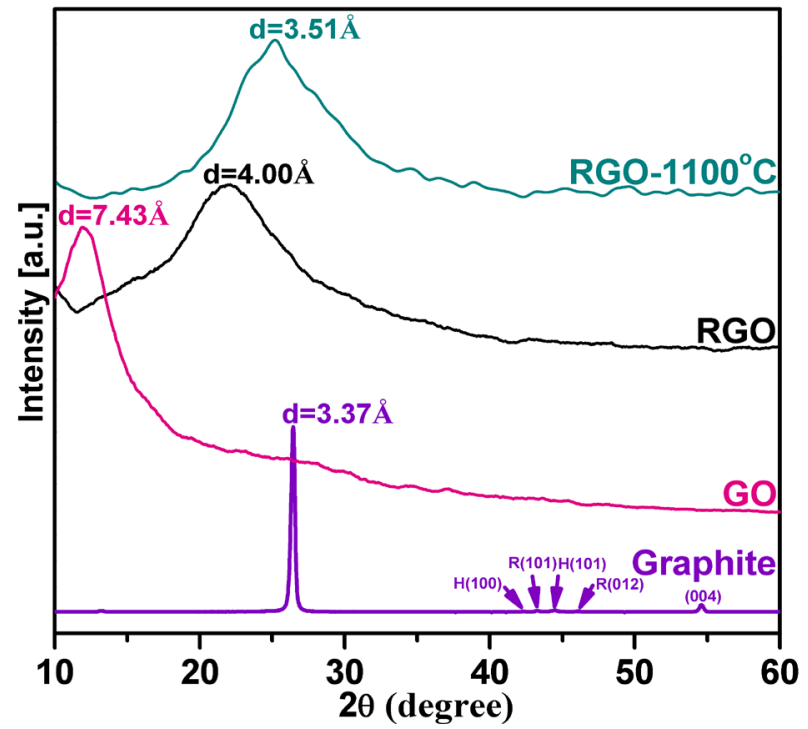

Figure 4. XRD patterns of raw graphite powders, GO, RGO and RGO- $1100^{\circ} \mathrm{C}$ films. 


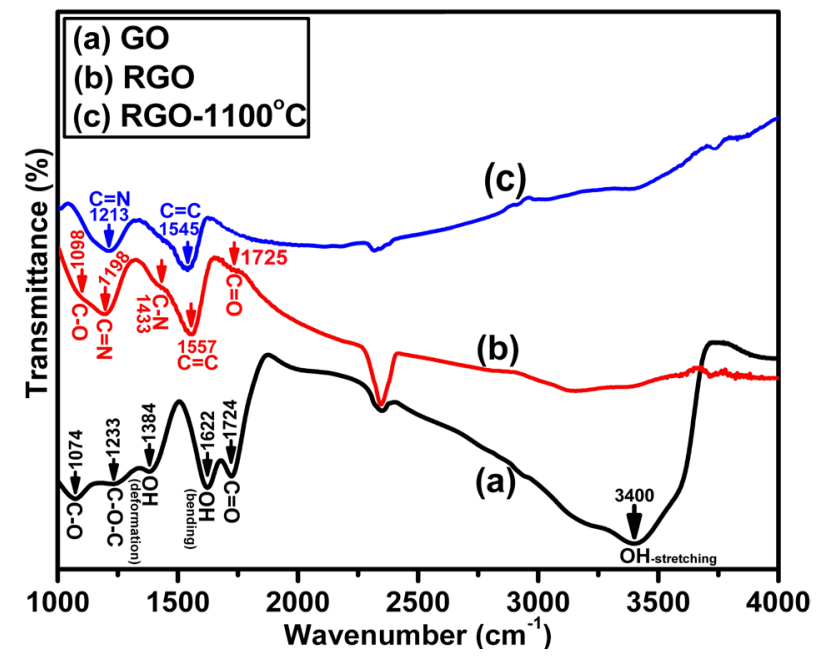

Figure 5. FT-IR spectra of (a) GO; (b) RGO; and (c) RGO- $1100^{\circ} \mathrm{C}$ films.

Figure 6 shows Raman spectra of graphite powders, GO, RGO and RGO- $1100^{\circ} \mathrm{C}$ films. It clearly indicates that the graphite powder has the best crystal quality. Graphite has a prominent $\mathrm{G}$ band at $1582 \mathrm{~cm}^{-1}$ which is assigned to the fist-order scattering of the $\mathrm{E}_{2 \mathrm{~g}}$ mode observed for $\mathrm{sp}^{2}$ carbon domains and broad $\mathrm{D}$ band at 1358 $\mathrm{cm}^{-1}$ is caused by sp ${ }^{3}$-hybridized carbon, structural defects, carbon amorphous or edge planes that can break the symmetry and selection rule [40]. In the Raman spectrum of GO, the band G band is broadened and shifted to $1602 \mathrm{~cm}^{-1}$, while the D band at $1352 \mathrm{~cm}^{-1}$ becomes prominent, indicating the destruction of conjugated system in graphite. After GO was chemically reduced, the D band became narrower and more prominent whilst the G band shifted from $1602 \mathrm{~cm}^{-1}$ to $1596 \mathrm{~cm}^{-1}$, possibly due to increase of the number of $\mathrm{sp}^{2}$ carbon in the graphene sheets. Moreover, after the subsequent thermal reduction at $1100^{\circ} \mathrm{C}$, the $\mathrm{G}$ band was further shifted to $1588 \mathrm{~cm}^{-1}$, suggesting that annealing removed the residual oxygen functional groups from the RGO sheets and more $\mathrm{sp}^{2}$ carbon networks were generated in the graphene sheet. The intensity ratio of $D$ band to $G$ band $\left(I_{D} / I_{G}\right)$ is usually used to measure degree of disordered carbon, as expressed by the $\mathrm{sp}^{3} / \mathrm{sp}^{2}$ carbon ratio [41] and an increase of $\mathrm{I}_{\mathrm{D}} / \mathrm{I}_{\mathrm{G}}$ means the degradation of crystallinity of graphitic materials. The $\mathrm{I}_{\mathrm{D}} / \mathrm{I}_{\mathrm{G}}$ ratios of graphite, $\mathrm{GO}, \mathrm{RGO}$ and RGO- $1100^{\circ} \mathrm{C}$ was calculated to be $0.10,0.85,1.11$ and 1.59 , respectively. The increase of $\mathrm{I}_{\mathrm{D}} / \mathrm{I}_{\mathrm{G}}$ can be attributed to a decrease in the average size but an increase in the number of $\mathrm{sp}^{2}$ domain upon reduction [42], but this effect obviously cannot be considered as the healing or repairing of defects in GO.

XPS is a powerful tool to identify the elemental composition in bulk materials. Furthermore, by analysis of binding energy (BE) values, the feature of binding between carbon and oxygen is confirmed. Figure 7 shows the XPS survey spectra of graphite powders, GO, RGO and RGO- $1100^{\circ} \mathrm{C}$ films. Only carbon, oxygen and nitrogen species are detected, the atomic percentage (at\%) of each element was calculated from the survey spectra, and the result was summarized in Table 1. In the survey scan XPS spectra, the peaks at around 285.5, 399.8 and $534.0 \mathrm{eV}$ correspond to C1s, N1s and O1s core-level, respectively. The effective reduction is clear because the content of oxygen atoms of RGO and RGO- $1100^{\circ} \mathrm{C}$ significantly reduces compared with GO. The oxygen content decreased in the order of GO $>$ RGO $>$ RGO- $1100^{\circ} \mathrm{C}$.

High resolution XPS of the as-made samples were further performed to analyze the change of individual groups during the reduction process; the relative composition of individual groups was estimated by the percentage of the certain group (the area of peak divided by the total area of all peaks). Figure 8 shows the high resolution C1s XPS spectra of graphite, GO, RGO and RGO- $1100^{\circ} \mathrm{C}$ films. For the graphite material, the C1s peak can be fitted to three components located at 284.5, 285.6 and $286.6 \mathrm{eV}$. The main peak at $284.5 \mathrm{eV}$ corresponds to binding energy of $\mathrm{sp}^{2}$ graphitic bonds $(\mathrm{C}=\mathrm{C})$, indicating that most of the carbon atoms in the graphite are arranged in a conjugated honeycomb lattice ( $89.9 \%$ area of $\mathrm{C}=\mathrm{C}$ bonds). The other two peaks located at 285.6 and $286.6 \mathrm{eV}$ are attributed to C-OH (hydroxyls) C-O-C (epoxy/ether) respectively. The C1s XPS spectrum of GO clearly indicates a considerable degree of oxidation with the content of oxygen element increased to 31.5 at\% while the area composition of $\mathrm{C}=\mathrm{C}$ bonds decreased to $52.0 \%$, which results from harsh oxidation and destruction of the $\mathrm{sp}^{2}$ atomic structure graphite [43] [44]. There are six different kinds of carbon atoms, located 


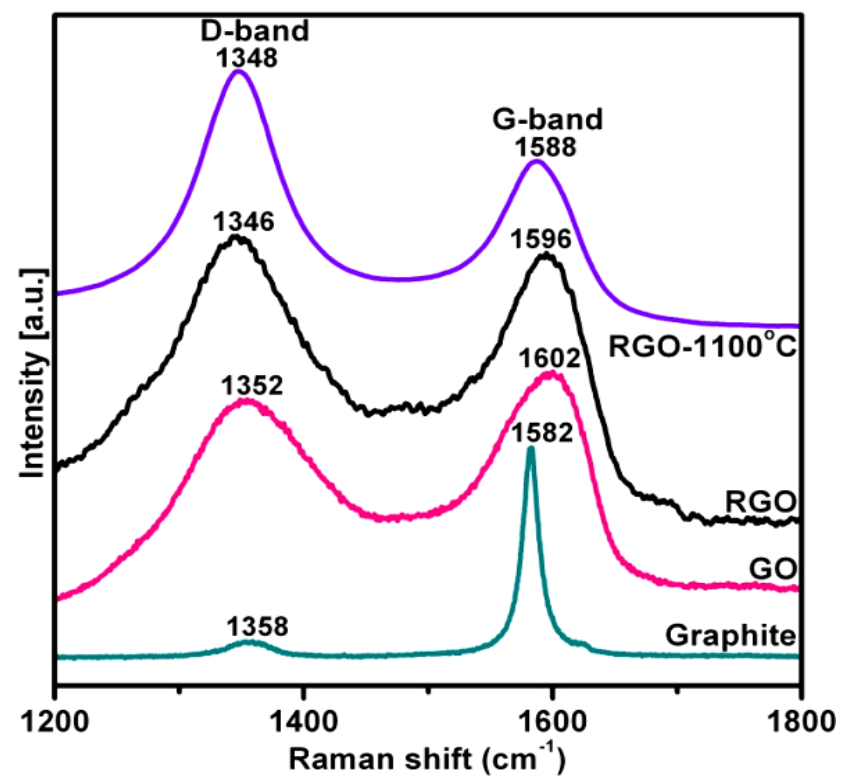

Figure 6. Raman spectra of raw graphite, GO, RGO and RGO- $1100^{\circ} \mathrm{C}$ films.

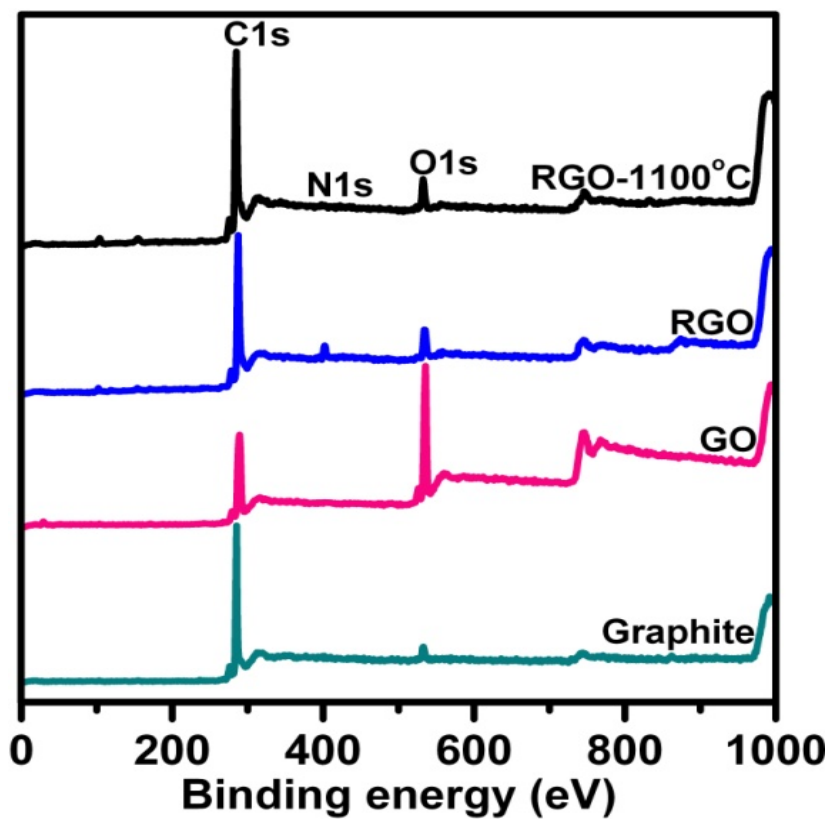

Figure 7. Wide-scan XPS spectra of graphite, GO, RGO and RGO- $1100^{\circ} \mathrm{C}$ films.

Table 1. Atomic concentration of C, N, and O of Graphite, GO, RGO and RGO- $1100^{\circ} \mathrm{C}$.

\begin{tabular}{|c|c|c|c|}
\hline Sample & C (\%) & N (\%) & $\mathbf{O}(\%)$ \\
\hline Graphite & 96.5 & -- & 3.5 \\
\hline GO-dried & 68.5 & -- & 31.5 \\
\hline RGO & 77.4 & 2.6 & 20.0 \\
\hline RGO- $1100^{\circ} \mathrm{C}$ & 94.8 & 1.2 & 4.0 \\
\hline
\end{tabular}



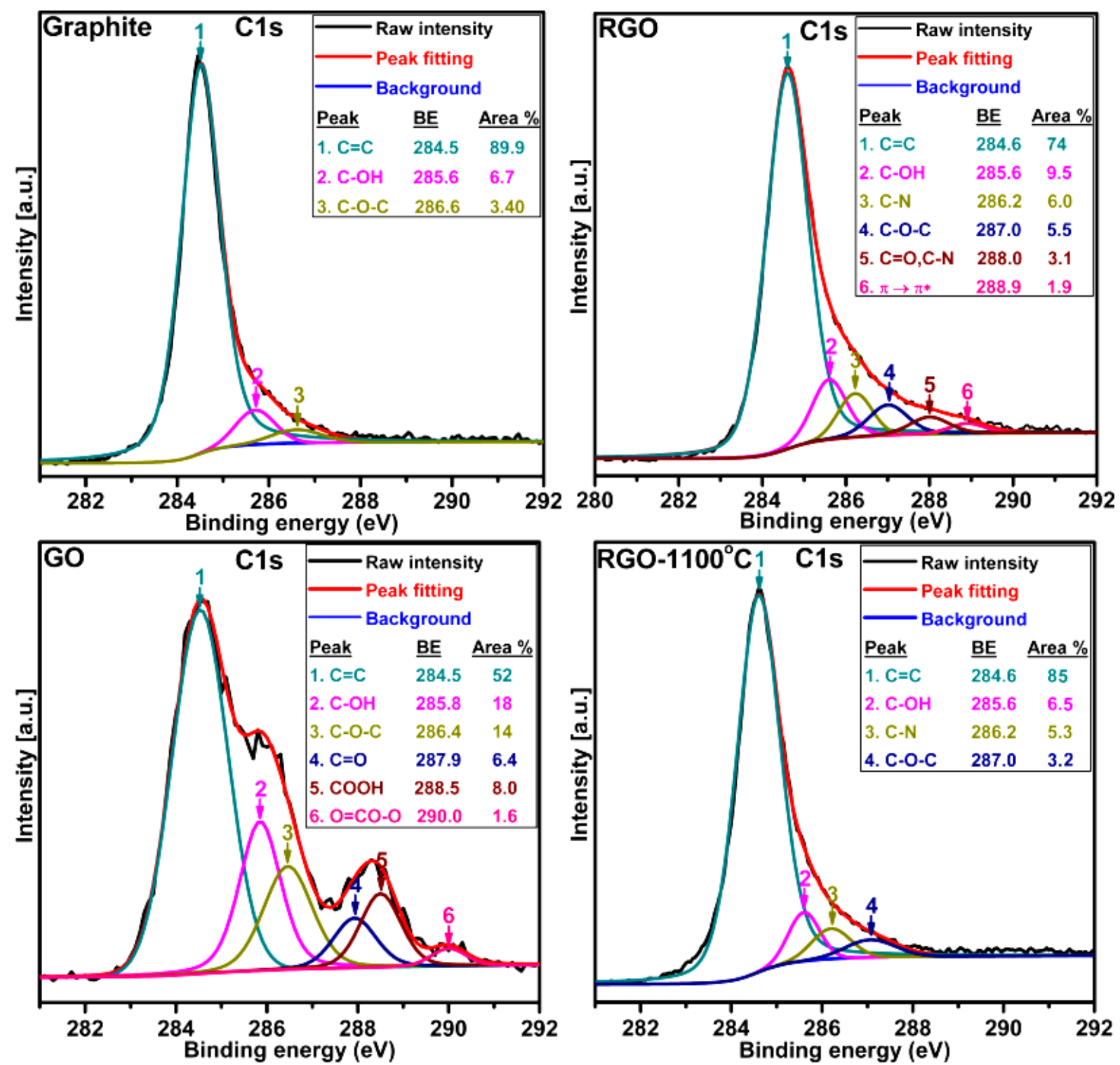

Figure 8. High resolution C1 XPS spectra of Graphite, GO, RGO and RGO- $1100^{\circ} \mathrm{C}$ films.

at 284.5, 285.8, 286.4, 287.9, 288.5 and $290.0 \mathrm{eV}$, correspondingly exist in different functional groups: C=C, $\mathrm{C}-\mathrm{OH}, \mathrm{C}-\mathrm{O}-\mathrm{C}, \mathrm{C}=\mathrm{O}, \mathrm{COOH}$ (acids) and $\mathrm{O}=\mathrm{CO}-\mathrm{O}$ (carbonates) groups, respectively. This indicated that the rich groups are contained within the GO. After chemical reduction of GO, the relative contribution of the components associated with oxygen was found to decrease very significant, this is in agreement with previous reports from the literature [9] [45]. It is worth noting that the content of oxygen element decreased to 20 at\% while the area composition of $\mathrm{C}=\mathrm{C}$ bonds increased to $70.0 \%$ in comparison to $\mathrm{GO}$, indicating a significant recovery of $\mathrm{sp}^{2}$ carbon network. In this case, the C1s peak can fitted to six components located at 284.6, 285.6, 286.2, 287.0, 288.0 and $288.9 \mathrm{eV}$. The peaks located at 284.6, 285.6 and $287.0 \mathrm{eV}$ correspond to energy of $\mathrm{C}=\mathrm{C}, \mathrm{C}-\mathrm{OH}$ and C-O-C groups, respectively. Concurrently, two new peaks at 286.2 and $288.0 \mathrm{eV}$ can be ascribed to two different C-N bonds, corresponding to the $\mathrm{N}-\mathrm{sp}^{2} \mathrm{C}$ and $\mathrm{N}-\mathrm{sp}^{3} \mathrm{C}$ bonds, respectively, originating from the substitution of the $\mathrm{N}$ atoms, defects or the edge of the graphene sheets [46] [47]. During the chemical reduction, oxygen functional groups in the as-made GO were responsible for reactions with hydrazine monohydrate $\left(\mathrm{NH}_{4} \mathrm{H}_{2} \mathrm{O}\right)$ to form C-N bonds. Additionally, it is remarkable that the $\pi \rightarrow \pi^{*}$ shakeup satellite peak around 288.9 eV, a characteristic of aromatic or conjugated systems, appeared after hydrazine reduction. Furthermore, after the thermal an- 
nealing, it is clearly found that the residual oxygen functional group (C-OH and $\mathrm{C}-\mathrm{O}-\mathrm{C}$ ) was considerably reduced and some of them even disappeared $(\mathrm{C}=\mathrm{O})$, meanwhile the composition of $\mathrm{C}=\mathrm{C}$ bonds was increased up to $85.0 \%$, clearly indicating the effeteness of thermal annealing in removing oxygen functional groups from GO and restoration of $\mathrm{sp}^{2}$ carbon networks. In addition, the intensity of the C-N peak was also reduced while the peak at $288.9 \mathrm{eV}\left(\pi \rightarrow \pi^{*}\right)$ disappeared in the spectrum of RGO- $1100^{\circ} \mathrm{C}$ sample.

\subsection{Electrical Property}

To study the electrical conductivity of the as-synthesized samples, we investigated the current-voltage (I-V) characteristic using four point probe with Keithley 2400 Source-meter. Figure 9 shows the I-V characteristic of GO, RGO and RGO- $1100^{\circ} \mathrm{C}$ samples. It is observed that all the samples exhibited linear I-V relation with the voltage in range of -1.0 to $+1.0 \mathrm{~V}$. The I-V slope of GO is close to zero. Before reduction, the GO behaved close-to-insulating material [48], which can be attributed to the high oxygen content in the form of functional groups contained by GO. It is widely known that the GO structure is predominantly amorphous due to distortions from high fraction of $\mathrm{sp}^{3}-\mathrm{O}$. Moreover, due to the random distribution, the $\mathrm{sp}^{2}$-hybridized benzene rings are separated by sp3-hybridized rings, thus leading to the insulating GO [49]. However, the I-V slope of RGO significantly increased after chemical reduction, indicating that the electrical conductivity of RGO was considerably enhanced. The enhanced electrical conductivity of RGO can be due to chemical removal of oxygen functional groups and simultaneous restoration of $\mathrm{sp}^{2}$ carbon networks during chemical reduction. However, the electrical conductivity of RGO is still lower than that of graphite [32]. It indicates that the structure of GO cannot be completely restored to graphitization by hydrazine monohydrate. To be suitable for practical applications, the conductivity of RGO needs to be improved. As a consequence of better ordering and additional deoxy-genation by thermal annealing at $1100^{\circ} \mathrm{C}$ in $\mathrm{H}_{2}$ ambient, the electrical conductively of RGO is found to further increase. The graphitization temperature of carbon materials is known to be $1100^{\circ} \mathrm{C}$ [13], at which the residual oxygen functional groups in RGO will be completely eliminated [50], contributing to the improvement of electrical conductivity. From the linear I-V curves the conductivity of GO, RGO and RGO- $1100^{\circ} \mathrm{C}$ was estimated to be $4.2 \times 10^{-4}, 24$ and $210 \mathrm{~S} / \mathrm{cm}$, corresponding to GO, RGO and RGO- $1100^{\circ} \mathrm{C}$, respectively, which is comparable to that presented by Geng et al. [51]. The I-V measurement data, in conjunction with XPS and Raman results, reveal that the conductivity of GO increased with increasing $\mathrm{sp}^{2}$ carbon content and with increasing $\mathrm{I}_{\mathrm{D}} / \mathrm{I}_{\mathrm{G}}$. A similar result was reported by Lopez et al. [52], in which it was observed that the CVD-GO exhibited an approximately linear rise of electrical conductively with increasing ID/IG. The improved electrical conductivity of GO by heating has been studied intensively [53][54].

\subsection{Sensing Property}

One of the most important issues of gas sensor is reproducibility. Therefore, the RGO and RGO- $1100^{\circ} \mathrm{C}$ based gas sensor developed in this research was exposed to a repeated cycling of the ambient gas with different nitrogen dioxide $\left(\mathrm{NO}_{2}\right)$ concentrations. Figure 10 shows the normalized change of current in the RGO and RGO$1100^{\circ} \mathrm{C}$ samples as function of time for different concentration of $\mathrm{NO}_{2}$ ranging from $10 \mathrm{ppm}$ increase to $50 \mathrm{ppm}$. $\mathrm{NO}_{2}$ appeared to act as a p-typed dopant [55] for both RGO and RGO- $1100^{\circ} \mathrm{C}$ films, resulting in a decrease in the resistance. The current of the RGO and RGO- $1100^{\circ} \mathrm{C}$ device increased with increasing flow of $\mathrm{NO}_{2}$. However, it is observed that the sensitivity of RGO- $1100^{\circ} \mathrm{C}$ based device to $\mathrm{NO}_{2}$ is higher than that of RGO, probably due to higher conductivity of RGO- $1100^{\circ} \mathrm{C}$ film. Similar results were found in the previous studies [56] [57]. The operational principle of graphene devices is based on changes in their electrical conductivity due to gas molecules adsorbed on graphene's surface and acting as donors or acceptors, similar to other solid-state sensors [3] [58]-[60]. It was further shown that the adsorbed molecules change the local carrier concentration in graphene one by one electron, which leads to step-like changes in resistance. In another study, it was observed that when graphene-gas sensor is exposed to $\mathrm{NO}_{2}$ gas molecules, the carrier concentration of graphene is changed which leads to the changes in the conductance, and consequently, in the current, this phenomenon is considered as sensing mechanism [61]. Based on this mechanism, Lu et al. [62] showed that the sensing behavior of the RGO was dependent on its electrical conductance. It was suggested that RGO was highly responsive to $\mathrm{NO}_{2}$ most likely due to the recovery of many graphitic carbon atoms as active sites for $\mathrm{NO}_{2}$ adsorption. Vacancies or small holes were probably created in thermal treatment and these defects may also serve as absorption sites for gaseous molecules [62]. It was known that the higher electrical conductance in the RGO, the more clusters 

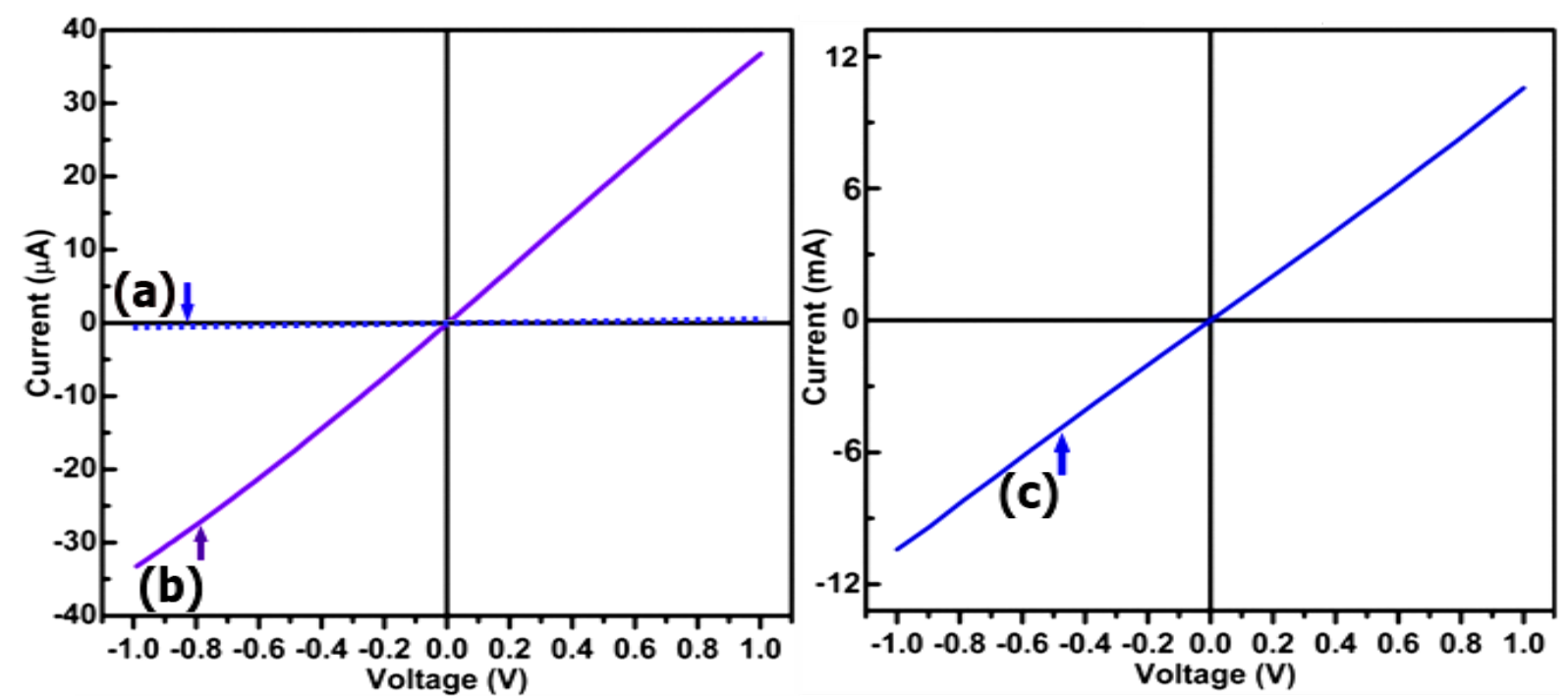

Figure 9. Current-voltage characteristics of (a) GO; (b) RGO; and (c) RGO- $1100^{\circ} \mathrm{C}$ films.
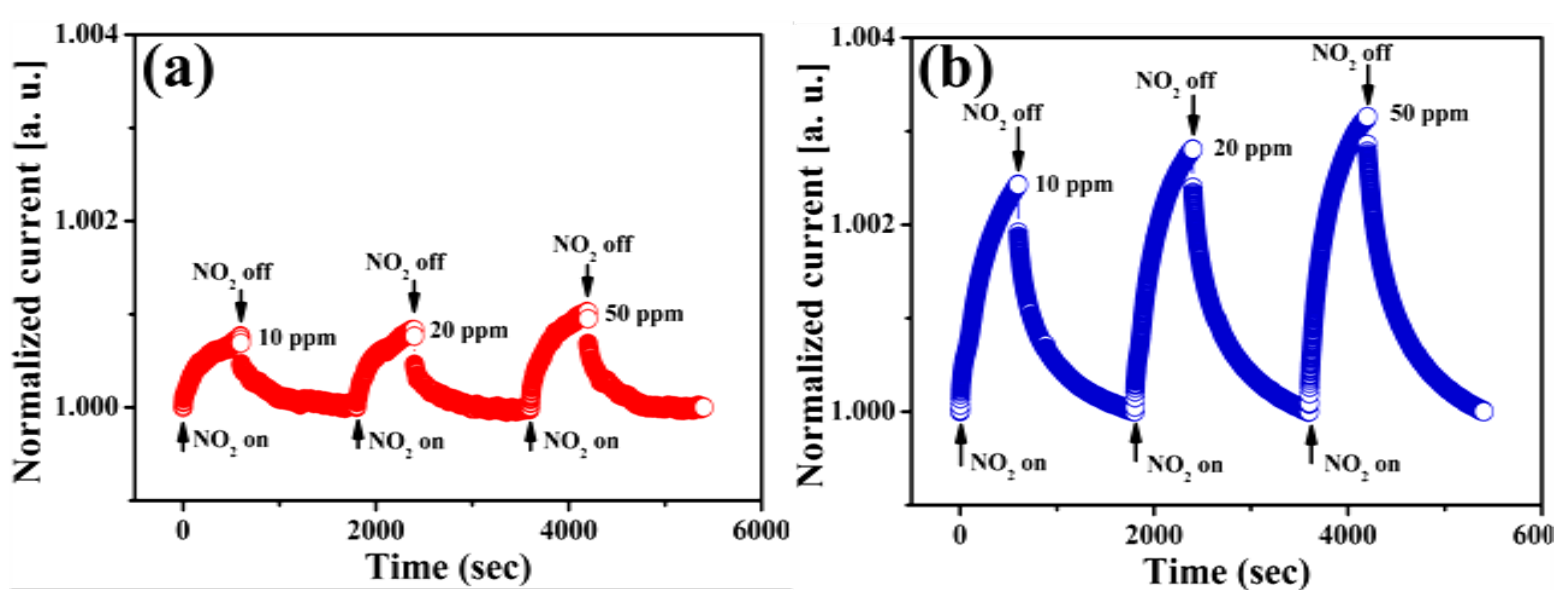

Figure 10. Reversibility and sensitivity of the (a) RGO and (b) RGO- $1100^{\circ} \mathrm{C}$ based sensor for detection of different concentrations of $\mathrm{NO}_{2}$ at $200^{\circ} \mathrm{C}$ in air.

of graphitic carbon atoms can be restored in the graphene, and thus better sensing behavior. Based on this result, it can be concluded that the RGO- $1100^{\circ} \mathrm{C}$ films have great potential for ultra-sensitive gas sensor by the optimization of device structure. The detection of a single gas molecule can be achieved by using RGO- $1100^{\circ} \mathrm{C}$ based gas sensor since the change in the electrical conductivity of the graphene is quantized in response to $\mathrm{NO}_{2}$ molecule [19]. Moreover, the sensitivity can be further improved by modification of RGO by adding noble metals [63] or metal oxides [64] [65].

\section{Conclusion}

Highly conductive graphene films were fabricated by spray deposition of the as-prepared RGO dispersion on the quartz substrate, followed by thermal treatment at $1100^{\circ} \mathrm{C}$ under $\mathrm{H}_{2}$ ambient. By analyzing XPS, Raman, XRD and FTIR spectra, it was found that the structure of GO was greatly changed upon reduction. Thermal treatment of RGO sheets resulted in further increasing $\mathrm{sp}^{2}$ carbon content, although decrease in the average size of $\mathrm{sp}^{2}$ domains $\left(\mathrm{I}_{\mathrm{D}} / \mathrm{I}_{\mathrm{G}}\right.$ increased). Therefore, the higher electrical conductivity of the RGO- $1100^{\circ} \mathrm{C}$ film compared with that of the RGO and GO films is likely attributed to the creation of more graphitic carbon atoms during the $1100^{\circ} \mathrm{C}$ annealing. Further, a tiny gas-sensor based on the RGO- $1100^{\circ} \mathrm{C}$ film exhibited great sensitivity and fast response to $\mathrm{NO}_{2}$ gas. The simple, low-cost and efficient method for the production of large quantities of gra- 
phene films described here could be developed for a variety of advanced applications, such as environmental monitoring, sensing in chemical processing plants, and gas detection for counter-terrorism.

\section{Acknowledgements}

This work was supported by the National Foundation for Science and Technology Development of Viet Nam (NAFOSTED, code 104.03.2013.39).

\section{References}

[1] Zhu, Y., Murali, S., Cai, W., Li, X., Suk, J.W., Potts, J.R. and Ruoff, R.S. (2010) Graphene and Graphene Oxide: Synthesis, Properties, and Applications. Advanced Materials, 22, 3906-3924. http://dx.doi.org/10.1002/adma.201001068

[2] Rao, C.N.R., Sood, A.K., Subrahmanyam, K.S. and Govindaraj, A. (2009) Graphene: The New Two-Dimensional Nanomaterial. Angewandte Chemie International Edition, 48, 7752-7777. http://dx.doi.org/10.1002/anie.200901678

[3] Basnayaka, P.A., Ram, M.K., Stefanakos, L. and Kumar, A. (2013) Graphene/Polypyrrole Nanocomposite as Electrochemical Supercapacitor Electrode: Electrochemical Impedance Studies. Graphene, 2, 81-87. http://dx.doi.org/10.4236/graphene.2013.22012

[4] Novoselov, K.S., Geim, A.K., Morozov, S.V., Jiang, D., Zhang, Y., Dubonos, S.V., Grigorieva, I.V. and Firsov, A.A. (2004) Electric Field Effect in Atomically Thin Carbon Films. Science, 306, 666-669. http://dx.doi.org/10.1126/science.1102896

[5] Hummers, W.S. and Offeman, R.E. (1958) Preparation of Graphitic Oxide. Journal of the American Chemical Society, 80, 1339. http://dx.doi.org/10.1021/ja01539a017

[6] Lerf, A., He, H., Forster, M. and Kliowski, J. (1998) Structure of Graphite Oxide Revisited. Journal of Physical Chemistry B, 102, 4477-4482. http://dx.doi.org/10.1021/jp9731821

[7] He, H., Riedl, T., Lerf, A. and Klinowski, J. (1996) Solid-State NMR Studies of the Structure of Graphite Oxide. Journal of Physical Chemistry, 100, 19954-19958. http://dx.doi.org/10.1021/jp961563t

[8] Watcharotone, S., Dikin, D.A., Stankovich, S., Piner, R., Jung, I., Dommett, G.H.B., Evmenenko, G., Wu, S.E., Chen, S.F., Liu, C.P., Nguyen, S.B.T. and Ruoff, R.S. (2007) Graphene-Silica Composite Thin Films as Transparent Conductors. Nano Letters, 7, 1888-1892. http://dx.doi.org/10.1021/nl070477+

[9] Eda, G., Fanchini, G. and Chhowalla, M. (2008) Large-Area Ultrathin Films of Reduced Graphene Oxide as a Transparent and Flexible Electronic Material. Nature Nanotechnology, 3, 270-274. http://dx.doi.org/10.1038/nnano.2008.83

[10] Gilje, S., Han, S., Wang, M., Wang, K.L. and Kaner, R.B. (2007) A Chemical Route to Graphene for Device Applications. Nano Letters, 7, 3394-3398. http://dx.doi.org/10.1021/nl0717715

[11] Li, D., Müller, M.B., Gilje, S., Kaner, R.B. and Wallace, G.G. (2008) Processable Aqueous Dispersions of Graphene Nanosheets. Nature Nanotechnology, 3, 101-105. http://dx.doi.org/10.1038/nnano.2007.451

[12] Wang, X., Zhi, L.J. and Muellen, K. (2008) Transparent, Conductive Graphene Electrodes for Dye-Sensitized Solar Cells. Nano Letters, 8, 323-327. http://dx.doi.org/10.1021/nl072838r

[13] Becerril, H.A., Mao, J., Liu, Z.F., Stoltenberg, R.M., Bao, Z.N. and Chen, Y.S. (2008) Evaluation of Solution-Processed Reduced Graphene Oxide Films as Transparent Conductors. ACS Nano, 2, 463-470. http://dx.doi.org/10.1021/nn700375n

[14] Novoselov, K.S., Geim, A.K., Morozov, S.V., Jiang, D., Katsnelson, M.I., Grigorieva, I.V., Dubonos, S.V. and Firsov, A.A. (2005) Two-Dimensional Gas of Massless Dirac Fermions in Graphene. Nature, 438, 197-200. http://dx.doi.org/10.1038/nature04233

[15] Berger, C., Song, Z.M., Li, X.B., Wu, X.S., Brown, N., Naud, C., Mayo, D., Li, T.B., Hass, J., Marchenkov, A.N., Conrad, E.H., First, P.N. and de Heer, W.A. (2006) Electronic Confinement and Coherence in Patterned Epitaxial Graphene. Science, 312, 1191-1196. http://dx.doi.org/10.1126/science.1125925

[16] Novoselov, K.S., McCann, E., Morozov, S.V., Fal’ko, V.I., Katsnelson, M.I., Zeitler, U., Jiang, D., Schedin, F. and Geim, A.K. (2006) Unconventional Quantum Hall Effect and Berry's Phase of $2 \pi$ in Bilayer Graphene. Nature Physics, 2, 177-180. http://dx.doi.org/10.1038/nphys245

[17] Zhang, Y.B., Small, J.P., Amori, M.E.S. and Kim, P. (2005) Electric Field Modulation of Galvanomagnetic Properties of Mesoscopic Graphite. Physical Review Letters, 94, Article ID: 176803. http://dx.doi.org/10.1103/PhysRevLett.94.176803

[18] Lemme, M.C., Echtermeyer, T.J., Baus, M. and Kurz, H. (2007) A Graphene Field-Effect Device. IEEE Electron Device Letters, 28, 282-284. http://dx.doi.org/10.1109/LED.2007.891668

[19] Schedin, F., Geim, A.K., Morozov, S.V., Hill, E.W., Blake, P., Katsnelson, M.I. and Novoselov, K.S. (2007) Detection 
of Individual Gas Molecules Adsorbed on Graphene. Nature Materials, 6, 652-655. http://dx.doi.org/10.1038/nmat1967

[20] Sundaram, R.S., Navarro, C.G., Balasubramanian, K., Burghard, M. and Kern, K. (2008) Electrochemical Modification of Graphene. Advanced Materials, 20, 3050-3053. http://dx.doi.org/10.1002/adma.200800198

[21] Ang, P.K., Chen, W., Wee, A.T.S. and Loh, K.P. (2008) Solution-Gated Epitaxial Graphene as pH Sensor. Journal of the American Chemical Society, 130, 14392-14393. http://dx.doi.org/10.1021/ja805090z

[22] Leenaerts, O., Partoens, B. and Peeters, F.M. (2008) Adsorption of $\mathrm{H}_{2} \mathrm{O}, \mathrm{NH}_{3}, \mathrm{CO}, \mathrm{NO}_{2}$, and NO on Graphene: A First-Principles Study. Physical Review B, 77, Article ID: 125416. http://dx.doi.org/10.1103/PhysRevB.77.125416

[23] Huang, B., Li, Z.Y., Liu, Z.R., Zhou, G., Hao, S.G., Wu, J., Gu, B.L. and Duan, W.H. (2008) Adsorption of Gas Molecules on Graphene Nanoribbons and Its Implication for Nanoscale Molecule Sensor. The Journal of Physical Chemistry C, 112, 13442-13446. http://dx.doi.org/10.1021/jp8021024

[24] Peng, S. and Cho, K. (2003) Ab Initio Study of Doped Carbon Nanotube Sensors. Nano Letters, 3, 513-517. http://dx.doi.org/10.1021/nl034064u

[25] Yeung, C.S., Liu, L.V. and Wang, Y.A. (2008) Adsorption of Small Gas Molecules onto Pt-Doped Single-Walled Carbon Nanotubes. The Journal of Physical Chemistry C, 112, 7401-7411. http://dx.doi.org/10.1021/jp0753981

[26] Ao, Z.M., Yang, J., Li, S. and Jiang, Q. (2008) Enhancement of CO detection in Al Doped Graphene. Chemical Physics Letters, 461, 276-279. http://dx.doi.org/10.1016/j.cplett.2008.07.039

[27] Qazi, M., Vogt, T. and Koley, G. (2007) Trace Gas Detection Using Nanostructured Graphite Layers. Applied Physics Letters, 91, Article ID: 233101. http://dx.doi.org/10.1063/1.2820387

[28] Jung, I., Dikin, D., Park, S., Cai, W., Mielke, S.L. and Ruoff, R.S. (2008) Effect of Water Vapor on Electrical Properties of Individual Reduced Graphene Oxide Sheets. The Journal of Physical Chemistry C, 112, 20264-20268. http://dx.doi.org/10.1021/jp807525d

[29] Robinson, J.T., Perkins, F.K., Snow, E.S., Wei, Z. and Sheehan, P.E. (2008) Reduced Graphene Oxide Molecular Sensors. Nano Letters, 8, 3137-3140. http://dx.doi.org/10.1021/nl8013007

[30] Fowler, J.D., Allen, M.J., Tung, V.C., Yang, Y., Kaner, R.B. and Weiller, B.H. (2009) Practical Chemical Sensors from Chemically Derived Graphene. ACS Nano, 3, 301-306. http://dx.doi.org/10.1021/nn800593m

[31] Wu, Z.S., Ren, W., Gao, L., Liu, B., Jiang, C. and Cheng, H.M. (2009) Synthesis of High-Quality Graphene with a Pre-Determined Number of Layers. Carbon, 47, 493-499. http://dx.doi.org/10.1016/j.carbon.2008.10.031

[32] Stankovich, S., Dikin, D.A., Piner, R.D., Kohlhaas, K.A, Kleinhammes, A., Jia, Y., Wu, Y., Nguyen, S.B.T. and Ruoff, R.S. (2007) Synthesis of Graphene-Based Nanosheets via Chemical Reduction of Exfoliated Graphite Oxide. Carbon, 45, 1558-1565. http://dx.doi.org/10.1016/j.carbon.2007.02.034

[33] Thema, F.T., Moloto, M.J., Dikio, E.D., Nyangiwe, N.N., Kotsedi, L., Maaza, M. and Khenfouch, M. (2013) Synthesis and Characterization of Graphene Thin Films by Chemical Reduction of Exfoliated and Intercalated Graphite Oxide. Journal of Chemistry, 2013, Article ID: 150536. http://dx.doi.org/10.1155/2013/150536

[34] Muthoosamy, K., et al. (2015) Exceedingly Biocompatible and Thin-Layered Reduced Graphene Oxide Nanosheets Using an Eco-Friendly Mushroom Extract Strategy. International Journal of Nanomedicine, 10, 1505-1519.

[35] Hung, P.V., Cuong, T.V., Hur, S.H., Shin, E.W., Kim, J.S., Chung, J.S. and Kim, E.J. (2010) Fast and Simple Fabrication of a Large Transparent Chemically-Converted Graphene Film by Spray-Coating. Carbon, 48, 1945-1951. http://dx.doi.org/10.1016/j.carbon.2010.01.062

[36] Hontorialucas, C., Lopezpeinado, A.J., Lopezgonzalez, J.D.D., Rojascervantes, M.L. and Martinaranda, R.M. (1995) Study of Oxygen-Containing Groups in a Series of Graphite Oxides: Physical and Chemical Characterization. Carbon, 33, 1585-1592. http://dx.doi.org/10.1016/0008-6223(95)00120-3

[37] Chandra, V. and Kim, K.S. (2011) Highly Selective Adsorption of $\mathrm{Hg}^{2+}$ by a Polypyrrole-Reduced Graphene Oxide Composite. Chemical Communications, 47, 3942-3944. http://dx.doi.org/10.1039/c1cc00005e

[38] Ricci, M., Trinquecoste, M., Auguste, F., Canet, R., Delhaes, P., Guimon, C., Pfister-Guillouzo, G., Nysten, B. and Issi, J.P. (1993) Relationship between the Structural Organization and the Physical Properties of PECVD Nitrogenated Carbons. Journal of Materials Research, 8, 480-488. http://dx.doi.org/10.1557/JMR.1993.0480

[39] Ren, Z.M., Lu, Y.F., Song, W.D., Chan, D.S.H., Low, T.S., Gamani, K., Chen, G. and Li, K. (1998) Studies of Carbon Nitride Thin Films Synthesized by KrF Excimer Ablation of Graphite in Nitrogen Atmosphere. MRS Proceedings, 526, 343-348. http://dx.doi.org/10.1557/PROC-526-343

[40] Ferrari, A.C., Meyer, J.C., Scardaci, V., Casiraghi, C., Lazzeri, M., Mauri, F., Piscanec, S., Jiang, D., Novoselov, K.S. and Roth, S. (2006) Raman Spectrum of Graphene and Graphene Layers. Physical Review Letters, 97, Article ID: 187401. http://dx.doi.org/10.1103/PhysRevLett.97.187401

[41] Ferrari, A.C. and Robertson, J. (2000) Interpretation of Raman Spectra of Disordered and Amorphous Carbon. Physi- 
cal Review B, 61, Article ID: 14095. http://dx.doi.org/10.1103/PhysRevB.61.14095

[42] Tuinstra, F. and Koenig, J.L. (1970) Raman Spectrum of Graphite. The Journal of Chemical Physics, 53, 1126-1130. http://dx.doi.org/10.1063/1.1674108

[43] Jiang, B.J., Tian, C.G., Wang, L., Xu, Y.X., Wang, R.H., Qiao, Y.J., Ma, Y.G. and Fu, H.G. (2010) Facile Fabrication of High Quality Graphene from Expandable Graphite: Simultaneous Exfoliation and Reduction. Chemical Communications, 46, 4920-4922. http://dx.doi.org/10.1039/c0cc00383b

[44] Chouciar, M., Thordarson, P. and Stride, J.A. (2009) Gram-Scale Production of Graphene Based on Solvothermal Synthesis and Sonication. Nature Nanotechnology, 4, 30-33. http://dx.doi.org/10.1038/nnano.2008.365

[45] Park, S., An, J., Piner, R.D., Jung, I., Yang, D., Velamakanni, A., Nguyen, S.B.T and Ruoff, R.S. (2008) Aqueous Suspension and Characterization of Chemically Modified Graphene Sheets. Chemistry of Materials, 20, 6592-6594. http://dx.doi.org/10.1021/cm801932u

[46] Wei, D.C., Liu, Y.Q., Yang, Y., Zhang, H.L., Huang, L.P. and Yu, G. (2009) Synthesis of N-Doped Graphene by Chemical Vapor Deposition and Its Electrical Properties. Nano Letters, 9, 1752-1758. http://dx.doi.org/10.1021/nl803279t

[47] Lee, D.H., Lee, W.J. and Kim, S.O. (2009) Highly Efficient Vertical Growth of Wall-Number-Selected, N-Doped Carbon Nanotube Arrays. Nano Letters, 9, 1427-1432. http://dx.doi.org/10.1021/nl803262s

[48] Gómez-Navarro, C., Weitz, R.T., Bittner, A.M., Scolari, M., Mews, A., Burghard, M. and Kern, K. (2007) Electronic Transport Properties of Individual Chemically Reduced Graphene Oxide Sheets. Nano Letters, 11, 3499-3503. http://dx.doi.org/10.1021/nl072090c

[49] Ren, P.G., Yan, D.X., Ji, X., Chen, T. and Li, Z.M. (2011) Temperature Dependence of Graphene Oxide Reduced by Hydrazine Hydrate. Nanotechnology, 22, Article ID: 055705. http://dx.doi.org/10.1088/0957-4484/22/5/055705

[50] Kinoshita, K. (1998) Carbon: Electrochemical and Physicochemical Properties. John Wiley \& Sons, New York, 560.

[51] Geng, J., Liu, L., Yang, S.B., Youn, S.C., Kim, D.W., Lee, J.S., Choi, J.K. and Jung, H.T. (2010) A Simple Approach for Preparing Transparent Conductive Graphene Films Using the Controlled Chemical Reduction of Exfoliated Graphene Oxide in an Aqueous Suspension. The Journal of Physical Chemistry C, 114, 14433-14440. http://dx.doi.org/10.1021/jp105029m

[52] Lopez, V., Sundaram, R.S., Gomez-Navarro, C., Olea, D., Burghard, M., Gomez-Herrero, J., Zamora, F. and Kern, K. (2009) Graphene Monolayers: Chemical Vapor Deposition Repair of Graphene Oxide: A Route to Highly-Conductive Graphene Monolayers. Advanced Materials, 21, 4683-4686. http://dx.doi.org/10.1002/adma.200990172

[53] Jin, M., Kim, T.H., Lim, S.C., Duong, D.L., Shin, H.J., Jo, Y.W., Jeong, H.K., Chang, J., Xie, S. and Lee, Y.H. (2011) Facile Physical Route to Highly Crystalline Graphene. Advanced Functional Materials, 21, 3496-3501. http://dx.doi.org/10.1002/adfm.201101037

[54] Wang, S.J., Geng, Y., Zheng, Q. and Kim, J.K. (2010) Fabrication of Highly Conducting and Transparent Graphene Films. Carbon, 48, 1815-1823. http://dx.doi.org/10.1016/j.carbon.2010.01.027

[55] Moser, J., Verdaguer, A., Jiménez, D., Barreiro, A. and Bachtold, A. (2008) The Environment of Graphene Probed by Electrostatic Force Microscopy. Applied Physics Letters, 92, Article ID: 123507. http://dx.doi.org/10.1063/1.2898501

[56] Ko, G., Kim, H.W., Ahn, J., Park, Y.M., Lee, K.Y. and Kim, J. (2010) Graphene-Based Nitrogen Dioxide Gas Sensors. Current Applied Physics, 10, 1002-1004. http://dx.doi.org/10.1016/j.cap.2009.12.024

[57] Yavari, F., Chen, Z., Thomas, A.V., Ren, W., Cheng, H.M. and Koratkar, N. (2011) High Sensitivity Gas Detection Using a Macroscopic Three-Dimensional Graphene Foam Network. Scientific Report, 1, Article No.: 166. http://dx.doi.org/10.1038/srep00166

[58] Moseley, P.T. (1997) Solid State Gas Sensors. Measurement Science and Technology, 8, 223-237. http://dx.doi.org/10.1088/0957-0233/8/3/003

[59] Kong, J., Franklin, N.R., Zhou, C., Chapline, M.G., Peng, S., Cho, K. and Dai, H. (2000) Nanotube Molecular Wires as Chemical Sensors. Science, 287, 622-625. http://dx.doi.org/10.1126/science.287.5453.622

[60] Collins, P.G., Bradley, K., Ishigami, M. and Zettl, A. (2000) Extreme Oxygen Sensitivity of Electronic Properties of Carbon Nanotubes. Science, 287, 1801-1804. http://dx.doi.org/10.1126/science.287.5459.1801

[61] Khaledian, M., Ismail, R., Saeidmanesh, M., Ghadiry, M. and Akbari, E. (2015) Sensitivity Modelling of Graphene Nanoscroll Based $\mathrm{NO}_{2}$ Gas Sensors. Plasmonics, 10, 1033-1040. http://dx.doi.org/10.1007/s11468-015-9905-6

[62] Lu, G., Ocola, L.E. and Chen, J.H. (2009) Gas Detection Using Low-Temperature Reduced Graphene Oxide Sheets. Applied Physics Letters, 94, Article ID: 083111. http://dx.doi.org/10.1063/1.3086896

[63] Penza, M., Gassano, G., Rossi, R., Alvisi, M., Rizzo, A., Signore, M.A., Dikonimos, T., Serra, E. and Giorgi, R. (2007) Enhancement of Sensitivity in Gas Chemiresistors Based on Carbon Nanotube Surface Functionalized with Noble Metal (Au, Pt) Nanoclusters. Applied Physics Letters, 90, Article ID: 173123. http://dx.doi.org/10.1063/1.2722207 
[64] Zhang, H., Feng, J.C., Fei, T., Liu, S. and Zhang, T. (2014) $\mathrm{SnO}_{2}$ Nanoparticles-Reduced Graphene Oxide Nanocomposites for $\mathrm{NO}_{2}$ Sensing at Low Operating Temperature. Sensors and Actuators B: Chemical, 190, 472-478. http://dx.doi.org/10.1016/j.snb.2013.08.067

[65] Qin, J.W., Cao, M.H., Li, N. and Hu, C.W. (2011) Graphene-Wrapped $\mathrm{WO}_{3}$ Nanoparticles with Improved Performances in Electrical Conductivity and Gas Sensing Properties. Journal of Materials Chemistry, 21, 17167-17171. http://dx.doi.org/10.1039/c1jm12692j 